\title{
Venlafaxine Versus Applied Relaxation for Generalized Anxiety Disorder: A Randomized Controlled Study on Clinical and Electrophysiological Outcomes
}

\author{
Daniele Zullino $\cdot$ Anne Chatton $\cdot$ Emmanuelle Fresard $•$ \\ Miroslava Stankovic • Guido Bondolfi • François Borgeat • \\ Yasser Khazaal
}

Published online: 3 December 2014

(C) Springer Science+Business Media New York 2014

\begin{abstract}
Some components of generalized anxiety disorder, such as physical symptoms, are thought to reflect autonomic nervous system arousal. This study primarily assessed the relationships between psychophysiological and clinical measures using venlafaxine extended release or applied relaxation, and secondarily, the impact of combination treatment in patients not remitting after 8 weeks. Fifty-eight patients were randomly assigned to 8 weeks of treatment with either venlafaxine or applied relaxation (Phase I). Non-remitted patients received combination treatment for an additional 8 weeks (Phase II). Assessments included the Hamilton Anxiety Scale (HAM-A), Beck Depression Inventory, Penn State Worry Questionnaire and the Stroop Color-Word Task coupled with electrophysiological measures (skin conductance and frontalis electromyography (EMG)). In Phase 1, a time effect was found for the clinical and skin conductance measures. Thirteen patients from each group were in remission. In Phase 2, seven additional patients remitted. Baseline psychophysiological measures were not associated with baseline clinical variables or with clinical outcomes. Independently of treatment allocation, a reduction in frontal EMG
\end{abstract}

D. Zullino · G. Bondolfi · Y. Khazaal

Geneva University Hospitals and Geneva University, Geneva, Switzerland

A. Chatton

Geneva University Hospitals, Geneva, Switzerland

E. Fresard

Lausanne University Hospitals, Lausanne, Switzerland

M. Stankovic

Cossonay, Switzerland

F. Borgeat

Louis-H Lafontaine Hospital, Montreal, Canada

Y. Khazaal $(\bowtie)$

Department of Mental Health and Psychiatry, Geneva University Hospitals and Geneva University, Grand Pré 70C, 1206 Geneva, Switzerland

e-mail: yasser.khazaal@hcuge.ch 
values at week 4 was significantly associated with a decrease in HAM-A scores at week 8. At week 4, responders from the applied relaxation group had lower electrophysiological activity than the venlafaxine group. Baseline psychophysiological measures were not linked with clinical measures at study inclusion or with treatment response. Frontal EMG response at week 4 is a possible predictor of treatment response. Treatment combination enhances treatment response after initial failure.

Keywords Antidepressant - Relaxation - Cognitive-behavior therapy · Electrophysiology $\cdot$ Skin conductance $\cdot$ Electromyogram

\section{Introduction}

Generalized anxiety disorder (GAD) is one of the most frequent mental illnesses [1, 2], frequently associated with disability [3] and with concomitant psychiatric and substance use disorders $[4,5]$. The core components of GAD are excessive and intrusive anxiety and worries related to different domains of current life (e.g. work, relationships, health) [6]. Worries were associated with attentional bias toward threat-related information [7]. Some GAD components, especially the physical features, are thought to reflect autonomic nervous system arousal, such as stress-induced increases in noradrenergic activity [8].

Increased muscle tension (particularly the frontalis muscle, which has been proposed to primarily reflect affective states [9] ) and altered electrodermal [10,11] responses to stressors have consistently been found in patients with anxiety disorders and have been correlated to catecholaminergic tone $[9,12]$. Hyperarousal, as well as muscular and autonomic symptoms, frequently accompany the typical increased apprehension in GAD. Electromyography (EMG) values of the frontalis muscle, however, were previously shown to change little under psychological stress [13]. In addition, patients with GAD have a diminished range of physiological responses to laboratory stressors in comparison to normal controls $[13,14]$. This diminished physiological level of response contrasts with the increased response of GAD patients when exposed to stimuli that specifically address their personal anxieties [15].

One antidepressant that has been approved for the treatment of GAD is venlafaxine [16, 17]. Venlafaxine and its active metabolite, Odesmethylvenlafaxine, are potent inhibitors of neuronal serotonin and norepinephrine reuptake and weak inhibitors of dopamine reuptake. They have no significant affinity for muscarinic, histaminergic, or alpha-adrenergic receptors in vitro [18]. Controlled studies have demonstrated the superiority of venlafaxine extended release (ER) over placebo in several measures of GAD symptoms [14, 19, 20].

As for other anxiety disorders [21-23], various cognitive behavioral therapies of GAD have been developed that involve components such as cognitive restructuring of worryrelated thoughts and/or relaxation training [24]. A study comparing cognitive restructuring, relaxation training, a combination of both, and a no-treatment group has shown equal improvement with the three active treatments [25]. Among several relaxation methods, the Jacobson progressive relaxation technique and its variants are among the best validated and most frequently used treatments in GAD patients, having been shown to improve worries and cognitive and somatic anxiety [26].

In consideration of the links between GAD symptoms and psychophysiological variables, and the possibility of treating GAD with venlafaxine or relaxation, we were interested in assessing the impact of these treatments on GAD symptoms and on 
psychophysiological variables. Our primary aim in the study was to assess the relationships between psychophysiological and clinical measures during venlafaxine ER treatment in comparison with relaxation therapy. Our secondary objective was to evaluate the impact of additional relaxation therapy in GAD patients not remitting responding to 8-week venlafaxine ER treatment and, conversely, the impact of additional venlafaxine ER treatment in patients not remitting to 8 -week relaxation therapy.

\section{Methods}

\section{Study Design}

This was a randomized, comparative, partial crossover study. Following screening and written informed consent, patients were randomly assigned to one of the following treatment groups: 8 weeks of venlafaxine ER treatment, or 8 weeks of weekly applied relaxation treatment (Phase I). Patients not responding remitting (Hamilton anxiety scale $[$ HAM-A] $>8$ ) to the first 8 weeks of treatment received combined treatment (venlafaxine ER plus applied relaxation) for a further 8 weeks (Phase II). Patient assessments were performed at baseline, 4 and 8 weeks (end of Phase I). Non-remitting patients received the combined treatment and were assessed at week 12 and week 16 (end of Phase II).

Between week 8 and 16, remitted patients continued on venlafaxine ER (if allocated to this treatment) or were encouraged to continue home practice of relaxation with the help of tape-recorded instructions (if allocated to applied relaxation).

\section{Inclusion Procedure and Criteria}

Patients were recruited through referrals from regional clinics and from psychiatrists and general practitioners in private practice, as well as through advertising in local newspapers. The Lausanne University Hospitals Ethic Committee Approved the Study

Patients had to be between 18 and 65 years old, capable of informed consent, meet the Diagnostic and Statistical Manual of Mental Disorders (DSM-IV) criteria for a diagnosis of GAD, have a score of at least 20 on the HAM-A, and have a negative serum pregnancy test at screening (for women of childbearing potential).

\section{Exclusion Criteria}

Exclusion criteria included intolerance to venlafaxine; history or presence of clinically significant hepatic, cardiovascular, renal, or other serious medical disease that might compromise patient safety; history or presence of bipolar disorder, schizophrenia, or other psychotic disorder; alcohol or drug dependence other than nicotine; current mental disorder due to a general medical condition; and women who were breast feeding, pregnant, or sexually active and not using a method of birth control.

Further exclusion criteria included use of venlafaxine or a monoamine oxidase inhibitor (MAOI) within 30 days of inclusion, an antidepressant other than an MAOI within 7 days of inclusion, or any psychotropic treatment of more than three consecutive days within the 7 days preceding randomization. Treatment with beta blockers was not allowed at inclusion or during the study. Furthermore, the introduction of, or change in, cognitive behavioral therapy or any other psychotherapy within 3 months preceding randomization was also an exclusion criterion. 
Allowed Concomitant Treatments

During the study, zaleplon or zolpidem (one dose nightly), benzodiazepines during the first 2 weeks, and short-term ( $<5$ days) treatments without psychotropic effects for allergies, colds, or flu were allowed. Other types of psychotherapy were allowed if they had been introduced more than 3 months earlier and if there was no change planned during the study period.

\section{Treatment Procedures}

\section{Venlafaxine ER}

Patients received $75 \mathrm{mg} /$ day of venlafaxine ER for 1 week. Thereafter, the dose was increased to $150 \mathrm{mg} /$ day in the absence of intolerable side effects. After 2 weeks, the dose was increased to $300 \mathrm{mg} /$ day (based on tolerability) for patients who did not achieve remission (HAM-A < 8). For Phase II, the same procedure was followed for patients from the relaxation group who were not in remission at week 8 .

\section{Applied Relaxation}

Patients receiving applied relaxation attended eight weekly individual 45-minute sessions. Between sessions, the homework assignment was for patients to practice relaxation $30 \mathrm{~min}$ per day with the help of a tape-recorded version of relaxation exercises. Applied relaxation sessions were given by a cognitive-behavioral psychotherapist.

\section{Measures}

Patients were assessed at each visit with the following instruments: HAM-A [27, 28], beck depression inventory (BDI) [29], and penn state worry questionnaire (PSWQ) [30, 31]. Adverse events and concomitant treatments were recorded at each visit.

\section{Psychophysiological Assessments}

The physiological data (skin conductance and frontalis EMG) were collected via a ProComp+/Biograph psychophysiological data acquisition system (Thought Technology, Montreal, Canada). Subjects' recordings were analyzed via the Biograph version 2.1 data collection program that accompanies ProComp+.

MyoScan-Pro Triode electrodes (silver/silver chloride) were used. They capture raw EMG signals at frequencies from 20 to $500 \mathrm{~Hz}$ and automatically convert the signals to root mean square signals, an analog rectification being done inside the circuitry. On the ProComp+, the EMG sensors were sampled at 32 samples/second. Frontalis EMG activity (in microvolts) was obtained following the preparation of the skin and placement of the electrodes over the muscle group.

Skin conductance (in MicroSiemens) was measured with a SC-Flex/Pro sensor and connected to a channel sampling at 32 samples/second. Two replaceable electrodes (silver/ silver chloride) were used that are sewn inside Velcro straps. The electrodes were placed on the volar surfaces of the index and middle fingers (middle segments) of the nondominant hand. 
Study participants were requested to do a Stroop Test. The Stroop Color-Word Task has been proposed as a valid paradigm for the evaluation of the anxiolytic activity of drugs [32] able to induce anxiety-related physiological reactions [32-35] and an increase in plasma and urinary adrenaline levels [33].

\section{Procedure}

Tests were conducted, individually, between 9:00 a.m. and 1:00 p.m. to control for diurnal variations. Participants were advised to have a light breakfast without caffeine-containing beverages. Upon arrival at the research laboratory, subjects first completed the psychometric scales. They were then seated in a comfortable armchair, shown the equipment, and given a brief description of the procedures. Instructions for completing the stress tasks were given before starting the experiment. During the task, subjects were asked to name the ink color of words presented to them on screen, disregarding their content.

The sequence of tasks is illustrated in Fig. 1 and has been used in previous studies [3638]. GAD patients are specifically known to be slow in naming the print color of threatrelated words [38]. The words were presented in red, green, yellow, orange, and blue on a black background on the computer screen. Each screen contained five different words in five colors in random order. Each screen was presented for $12 \mathrm{~s}$.

\section{Analysis}

Statistical analysis was performed using SPSS for Windows (Statistical Package for the Social Sciences, version 15.0). An initial exploratory analysis involved the calculation of proportions, as well as means and standard deviation, to describe the baseline characteristics. Chi square tests and $t$ tests were used to test for differences between the two treatment groups. Analyses of variance (ANOVAs) for repeated measures were used in Phase I and Phase II to measure the evolution of the BDI, HAM-A, and PSWQ scores at baseline, week 4 , and week 8 , as well as the evolution of the psychophysiological measures. Friedman non-parametric tests were also used when the necessary conditions of variance homogeneity were not met in order to assess the evolution of the above-cited measures.

\section{Results}

A total of 185 patients were screened, of whom 58 were included and randomized (Fig. 2) to venlafaxine ER or applied relaxation. No baseline differences were found between treatment groups (Tables 1,2).
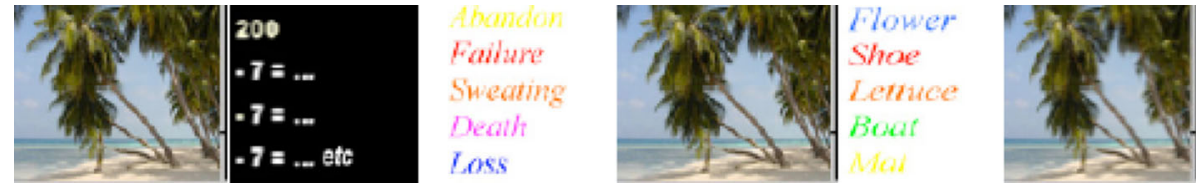

Fig. 1 Modified stroop task 


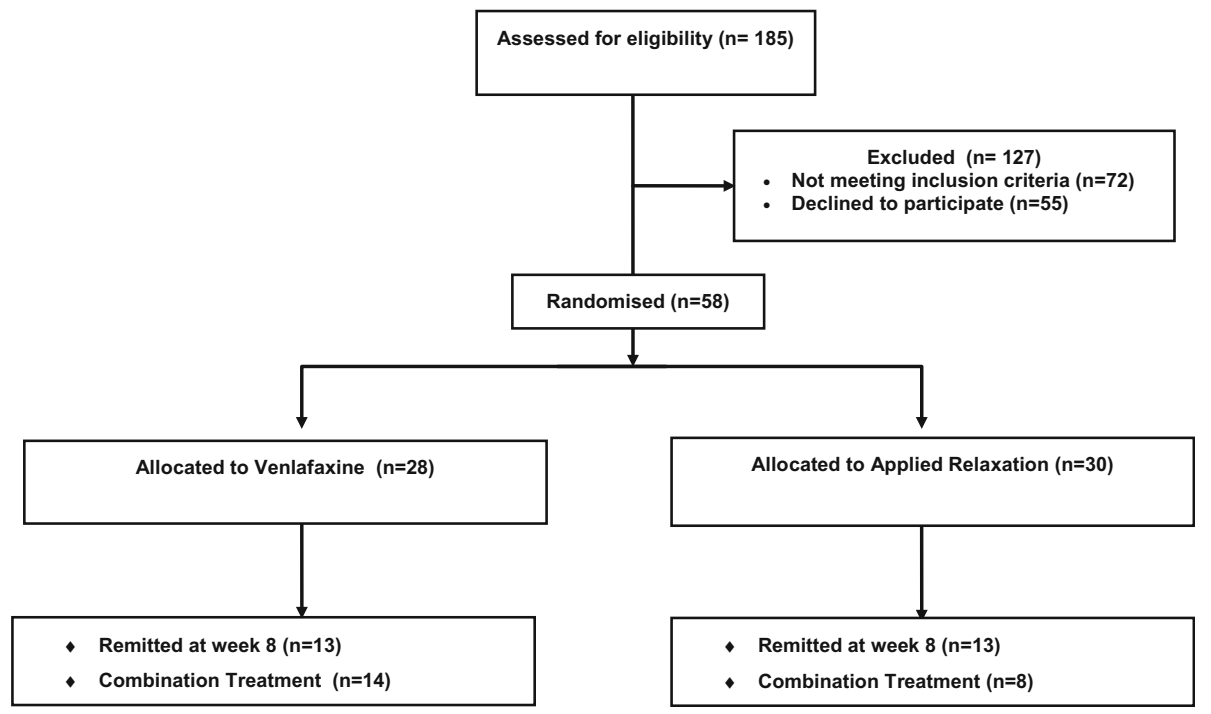

Fig. 2 Study flowchart

Table 1 Baseline clinical characteristics of the sample

\begin{tabular}{|c|c|c|c|c|c|}
\hline & Venlafaxine & Relaxation & & & \\
\hline Characteristic & $(\mathrm{n}=30)$ & $(n=28)$ & Statistics & $d f$ & $P$ \\
\hline Age, mean (SD) & $44.9(8)$ & $45.6(11.3)$ & $\mathrm{t}=-0.3$ & 56 & 0.8 \\
\hline Male, $\%$ & 63.3 & 53.6 & $\chi^{2}=0.5$ & 1 & 0.5 \\
\hline Unemployed, \% & 20 & 25 & $\chi^{2}=0.3$ & 1 & 0.6 \\
\hline Living alone, $\%$ & 26.7 & 21.4 & $\chi^{2}=0.2$ & 1 & 0.8 \\
\hline Smokers, \% & 36.7 & 14.3 & $\chi^{2}=3.8$ & 1 & 0.07 \\
\hline Alcohol users, \% & 36.7 & 51.9 & $\chi^{2}=1.3$ & 1 & 0.3 \\
\hline Coffee users, $\%$ & 76.7 & 71.4 & $\chi^{2}=0.2$ & 1 & 0.6 \\
\hline Previous hospitalizations, mean (SD) & $0.1(0.3)$ & $0.1(0.3)$ & $\mathrm{t}=0.3$ & 56 & 0.8 \\
\hline \multicolumn{6}{|l|}{ Time since the beginning of GAD, $\%$} \\
\hline$<10$ years & 43.3 & 53.6 & & & \\
\hline$\geq 10$ years & 46.7 & 35.7 & $\chi^{2}=0.7$ & 1 & 0.4 \\
\hline Unclear & 10 & 10.7 & & & \\
\hline HAM-A total score, mean (SD) & $24.3(5.7)$ & $21.8(7.6)$ & $\mathrm{t}=1.4$ & 54 & 0.2 \\
\hline PSWQ total score, mean (SD & $50(5.7)$ & $48.5(5)$ & $\mathrm{t}=1$ & 54 & 0.5 \\
\hline BDI total score, mean (SD) & $12.5(6.7)$ & $11.3(5.6)$ & $\mathrm{t}=0.7$ & 54 & 0.5 \\
\hline
\end{tabular}

$D f$ degree of freedom, $G A D$ generalized anxiety disorder, $H A M-A$ hamilton anxiety scale, $P S W Q$ penn state worry questionnaire, $S D$ standard deviation, $B D I$ beck depression inventory

\section{Dropout}

At week 8, the dropout rates were $10 \%$ in the venlafaxine ER group and $25 \%$ in the applied relaxation group, with no statistically significant difference between groups $\left(\chi^{2}=2.3, d f=1, P=0.1\right)$. Patients who dropped out did not differ significantly from the others on any measure. 
Table 2 Baseline psychophysiological characteristics of the sample

\begin{tabular}{llllll}
\hline & $\begin{array}{l}\text { Venlafaxine } \\
(n=30)\end{array}$ & $\begin{array}{l}\text { Relaxation } \\
(n=28)\end{array}$ & Statistics & $d f$ & $P$ \\
\hline Frontal EMG: neutral words & $5(2.7)$ & $4.5(2.9)$ & $t=0.6$ & 54 & 0.6 \\
Frontal EMG: relaxation 2 & $2.8(1.4)$ & $3(2.2)$ & $t=-0.5$ & 55 & 0.6 \\
Frontal EMG: anxiety-related words & $6.4(7.2)$ & $6(6.4)$ & $t=0.2$ & 53 & 0.9 \\
Frontal EMG: relaxation 3 & $3.1(2.2)$ & $3.4(3.9)$ & $t=-1$ & 53 & 0.3 \\
Frontal EMG: calculation & $5.8(5.2)$ & $4.7(3)$ & $t=0.9$ & 53 & 0.4 \\
Frontal EMG: relaxation 4 & $3.4(1.9)$ & $4.2(3.7)$ & $t=-1.1$ & 53 & 0.3 \\
Skin conductance: relaxation 1 & $1.4(1)$ & $1(0.8)$ & $t=2$ & 52 & 0.05 \\
Skin conductance: neutral words & $2.1(1.4)$ & $1.8(1.4)$ & $t=0.9$ & 55 & 0.4 \\
Skin conductance: relaxation 2 & $1.9(1.4)$ & $1.6(1.3)$ & $t=0.9$ & 55 & 0.3 \\
Skin conductance: anxiety-related words & $2.6(1.9)$ & $2(1.6)$ & $t=1.1$ & 53 & 0.3 \\
Skin conductance: relaxation 3 & $2.2(1.7)$ & $1.6(1.3)$ & $t=1.5$ & 53 & 0.2 \\
Skin conductance: calculation & $2.5(1.9)$ & $2(1.6)$ & $t=1.1$ & 53 & 0.3 \\
Skin conductance: relaxation 4 & $2.1(1.6)$ & $1.7(1.4)$ & $t=1.1$ & 53 & 0.3 \\
\hline
\end{tabular}

$d f$ degree of freedom, $E M G$ electromyography

Main Effects on Clinical and Psychophysiological Measures

\section{Phase 1}

Outcomes of Phase I are presented in Table 3. ANOVAs for repeated measures from baseline to week 8 in the Phase 1 study show a statistically significant effect of time on the assessed clinical measures: BDI $(F=17, P<0.0005)$, HAM-A total score $(F=58.4$, $P<0.0005)$, HAM-A somatic anxiety subscores $(F=33.5, P<0.0005)$, HAM-A psychic anxiety scores $(F=59.7, P<0.0005)$, and PSWQ $(F=15, P<0.0005)$.

Most of the observed effects were due to the decrease between baseline and week 4 : BDI $(F=15.6, P<0.0005)$, HAM-A total score $(F=59.1, P<0.0005)$, HAM-A somatic subscore $(F=27, P<0.0005)$, HAM-A psychic anxiety $(F=72.4, P<0.0005)$, and PSWQ $(F=22, P<0.0005)$. Further improvements were found between week 4 and week 8 for the HAM measures: HAM-A $(F=10.7, P=0.002)$, HAM-A somatic $(F=9.4, P=0.004)$, and HAM-A psychic $(F=6.7, P=0.01)$. No time $\times$ group effect was observed. Intent-to-treat analyses were performed for the above outcomes and led to similar conclusions.

At week 8, 13 patients (43.3\%) allocated to the venlafaxine ER group and $13(46.4 \%)$ allocated to the applied relaxation group were in remission (HAM-A $<8$ ). The remaining patients were reassigned to the combined treatment.

From baseline to week 8 , the evolution of psychophysiological variables was also assessed with ANOVA for repeated measures. An overall time effect was observed for skin conductance in each of the assessed conditions: relaxation $(F=8.2, P=0.001)$, neutral words $(F=8.6, P=0.001)$, anxiety-related words $(F=10.6, P<0.0005)$, and calculation $(F=8.9, P=0.001)$. For each of the experimental conditions, the following effects were observed between baseline and week 4: relaxation $(F=11.2, P=0.002)$, neutral words $(F=9.7, P=0.003)$, anxiety-related words $(F=11.2, P=0.002)$, and calculation $(F=8.7, P=0.005)$; in addition, the following effects were seen between week 4 
Table 3 Clinical and psychophysiological outcome variables during Phase I treatment

\begin{tabular}{|c|c|c|c|c|c|c|}
\hline & \multicolumn{3}{|c|}{ Venlafaxine $(n=30)$} & \multicolumn{3}{|c|}{ Relaxation $(n=28)$} \\
\hline & Baseline & Week 4 & Week 8 & Baseline & Week 4 & Week 8 \\
\hline BDI & $12.5(6.7)$ & $8.1(5.4)$ & $7(6.2)$ & $11.4(5.6)$ & $7.5(6.4)$ & $5.4(5.3)$ \\
\hline HAM-A & $24.3(5.7)$ & $13(5.7)$ & $10.5(6.5)$ & $21.8(7.6)$ & $13(8)$ & $8.1(6.3)$ \\
\hline PSWQ & $49.9(5.7)$ & $41.9(6.8)$ & $40.7(9)$ & $48.5(5)$ & $45.3(6.4)$ & $42(8.5)$ \\
\hline Frontal EMG: neutral words & $5(2.7)$ & $4.8(2)$ & $4.4(2.8)$ & $4.5(2.9)$ & $5(3)$ & $5.3(2.7)$ \\
\hline Frontal EMG: relaxation 2 & $2.8(1.4)$ & $3(2.1)$ & $2.8(1.2)$ & $3(2.2)$ & $3(2)$ & $3.7(3.2)$ \\
\hline $\begin{array}{l}\text { Frontal EMG: anxiety-related } \\
\text { words }\end{array}$ & $6.4(7.2)$ & $4.6(2.6)$ & $4.6(3.4)$ & $6(6.4)$ & $4.3(2.5)$ & $5.1(3.6)$ \\
\hline Frontal EMG: relaxation 3 & $3.1(2.2)$ & $3(1.1)$ & $2.8(1.3)$ & $3.4(3.9)$ & $3(1.9)$ & $3.3(2.3)$ \\
\hline Frontal EMG: calculation & $5.8(5.2)$ & $4.7(2.7)$ & $5.2(4.3)$ & $4.7(3)$ & $4.6(2.5)$ & $4.9(3.8)$ \\
\hline Frontal EMG: relaxation 4 & $3.4(1.9)$ & $3(1.1)$ & $3.4(2.2)$ & $4.2(3.7)$ & $3.7(3)$ & $3.3(3)$ \\
\hline Skin conductance: relaxation 1 & $1.4(1)$ & $1.3(0.8)$ & $1(0.5)$ & $1(0.8)$ & $0.8(0.6)$ & $0.7(0.4)$ \\
\hline Skin conductance: neutral words & $2.1(1.4)$ & $2(1.2)$ & $1.4(0.8)$ & $1.8(1.4)$ & $1.2(0.9)$ & $1.1(0.7)$ \\
\hline Skin conductance: relaxation 2 & $1.9(1.4)$ & $1.7(1.2)$ & $1.2(0.7)$ & $1.6(1.3)$ & $1(0.8)$ & $1(0.6)$ \\
\hline $\begin{array}{l}\text { Skin conductance: anxiety- } \\
\text { related words }\end{array}$ & $2.6(1.9)$ & $2.2(1.3)$ & $1.5(0.9)$ & $2(1.6)$ & $1.5(1.1)$ & $1.1(0.7)$ \\
\hline Skin conductance: relaxation 3 & $2.2(1.7)$ & $1.8(1.2)$ & $1.3(0.7)$ & $1.6(1.3)$ & $1.2(0.9)$ & $1(0.6)$ \\
\hline Skin conductance: calculation & $2.5(1.9)$ & $2.2(1.5)$ & $1.5(0.9)$ & $2(1.6)$ & $1.5(1.1)$ & $1.1(0.7)$ \\
\hline Skin conductance: relaxation 4 & $2.1(1.6)$ & $1.9(1.3)$ & $1.3(0.7)$ & $1.7(1.4)$ & $1.3(1)$ & $1(0.6)$ \\
\hline
\end{tabular}

$B D I$ beck depression inventory, $H A M-A$ hamilton anxiety scale, $P S W Q$ penn state worry questionnaire, $E M G$ electromyography

and week 8: relaxation $(F=4.3, P=0.04)$, neutral words $(F=4.1, P=0.05)$, anxietyrelated words $(F=8.3, P=0.006)$, and calculation $(F=7.7, P=0.008)$. No other statistically significant differences were observed either for time effect or for time $\times$ group effect.

\section{Phase 2}

During Phase 2, the addition of the alternative therapy led to the remission (HAM-A $<8$ ) of seven more patients (31.8\%). The evolution of the clinical measures (BDI, HAM-A, and PSWQ) and the psychophysiological variables at week 8, week 12, and week 16 were assessed with ANOVA for repeated measures with treatment group as factor. Friedman non-parametric tests were also used when the necessary conditions of variance homogeneity were not met in order to assess the evolution of the above-cited measures. Phase II outcomes are presented in Table 4.

The results show a statistically significant time effect on the following variables: BDI $(F=3.8, P=0.03)$, HAM-A total score $(F=5.4, P=0.02)$, and HAM-A psychic anxiety scores $(F=6, P=0.01)$. The observed effects can mainly be explained by a diminution of scores between week 8 and week 12: BDI $(F=6.5, P=0.02)$, HAM-A total score $(F=4.8, P=0.048)$, and HAM-A psychic anxiety scores $(F=7.7$, $P=0.01)$. No other statistically significant difference was observed. 
Table 4 Clinical and psychophysiological outcome variables during Phase II treatment

\begin{tabular}{|c|c|c|c|c|c|c|}
\hline & \multicolumn{3}{|c|}{ Venlafaxine $^{\mathrm{a}}(n=14)$} & \multicolumn{3}{|c|}{ Relaxation $^{\mathrm{a}}(n=8)$} \\
\hline & Week 8 & Week12 & Week 16 & Week 8 & Week 12 & Week 16 \\
\hline BDI & $8.4(7.0)$ & $7.7(6.0)$ & $7.7(8.9)$ & $7(6.5)$ & $4.1(3.9)$ & $3.3(3.9)$ \\
\hline HAM-A & $13.9(6.1)$ & $12.2(5.1)$ & $9.3(5.8)$ & $13(6.7)$ & $9.6(6.4)$ & $6.2(7)$ \\
\hline PSWQ & $44.2(8.8)$ & $42.6(9.7)$ & $38.4(8.7)$ & $42.9(9.2)$ & $38(9.4)$ & $32.9(10.4)$ \\
\hline Frontal EMG: relaxation 1 & $2.9(1.3)$ & $3.1(2.2)$ & $3.5(1.6)$ & $3.4(2.9)$ & $2.9(0.6)$ & $3(2)$ \\
\hline Frontal EMG: neutral words & $4.4(2.8)$ & $4.2(2.5)$ & $4.8(2.6)$ & $5.3(2.7)$ & $7.7(6.8)$ & $4.5(2.9)$ \\
\hline Frontal EMG: relaxation 2 & $2.8(1.2)$ & $2.4(1.1)$ & $3.2(1.9)$ & $3.7(3.2)$ & $3.9(1.1)$ & $2.7(2.1)$ \\
\hline $\begin{array}{l}\text { Frontal EMG: anxiety-related } \\
\text { words }\end{array}$ & $4.6(3.4)$ & $3.9(3.9)$ & $4.8(3.9)$ & $5.1(3.6)$ & $5.9(3.4)$ & $3.9(3)$ \\
\hline Frontal EMG: relaxation 3 & $2.8(1.3)$ & $3.3(3)$ & $3.4(2.5)$ & $3.3(2.3)$ & $3.2(1.6)$ & $4.4(3.8)$ \\
\hline Frontal EMG: calculation & $5.2(4.3)$ & $4(3)$ & $5.6(4.5)$ & $4.9(3.8)$ & $5.8(3.8)$ & $4.2(3.5)$ \\
\hline Frontal EMG: relaxation 4 & $3.4(2.2)$ & $2.5(1.3)$ & $3.9(2.9)$ & $3.3(3)$ & $2.7(0.8)$ & $3.1(2.3)$ \\
\hline Skin conductance: relaxation 1 & $1(0.5)$ & $0.9(0.4)$ & $1(0.5)$ & $0.7(0.4)$ & $0.8(0.4)$ & $1.1(1)$ \\
\hline $\begin{array}{l}\text { Skin conductance: neutral } \\
\text { words }\end{array}$ & $1.4(0.8)$ & $1.2(0.7)$ & $1.6(0.8)$ & $1.1(0.7)$ & $1.2(0.7)$ & $1.5(1.4)$ \\
\hline Skin conductance: relaxation 2 & $1.2(0.7)$ & $1.1(0.5)$ & $1.2(0.7)$ & $1(0.6)$ & $1.1(0.6)$ & $1.4(1.4)$ \\
\hline $\begin{array}{l}\text { Skin conductance: anxiety- } \\
\text { related words }\end{array}$ & $1.5(0.9)$ & $1.4(0.8)$ & $1.6(0.9)$ & $1.1(0.7)$ & $1.4(0.9)$ & $1.7(1.6)$ \\
\hline Skin conductance: relaxation 3 & $1.3(0.7)$ & $1.1(0.6)$ & $1.3(0.7)$ & $1(0.6)$ & $1.2(0.8)$ & $1.5(1.5)$ \\
\hline Skin conductance: calculation & $1.5(0.9)$ & $1.5(0.9)$ & $1.7(1.1)$ & $1.1(.07)$ & $1.4(1)$ & $1.7(1.5)$ \\
\hline Skin conductance: relaxation 4 & $1.3(0.7)$ & $1.2(0.6)$ & $1.4(0.8)$ & $1(0.6)$ & $1.4(1.1)$ & $1.6(1.8)$ \\
\hline
\end{tabular}

$B D I$ beck depression inventory, $H A M-A$ hamilton anxiety scale, $P S W Q$ penn state worry questionnaire, $E M G$ electromyography

${ }^{a}$ Treatment harm before combination of both treatments

Links Between Psychophysiological Measures and Clinical Outcomes

\section{Baseline}

At baseline, Pearson correlations, after Bonferroni correction, showed no statistically significant association between clinical variables (BDI, HAM-A, and PSWQ) and electrophysiological variables.

\section{Phase 1}

Pretreatment levels of psychophysiological reactivity were not associated with remission (HAM-A $<8$ ) or response (a $50 \%$ decrease in HAM-A) at week 8, as assessed by oneway ANOVA. Furthermore, there was no association between baseline psychophysiological variables and HAM-A or PSWQ scores at week 8, as assessed by multiple regressions using electrophysiological measures and treatment groups as variables. Moreover, no group effect was found. 
Links Between Psychophysiological Evolution at Week 4 and Remission at Week 8

Early psychophysiological modifications (changes between baseline and week 4) were tested as predictors of remission at week 8. ANOVA models with repeated measures (baseline, week 4) were performed using treatment group and remission at week 8 as factors. A treatment group $\times$ time effect was found for skin conductance for the neutral words condition $(F=4.8 ; P=0.04)$. A similar group $\times$ time was found for frontal EMG for the calculation condition $(F=6.9, P=0.01)$ and for the anxiety-related words condition $(F=13.5, P=0.001)$. The applied relaxation group had lower mean scores in comparison with the venlafaxine ER group.

\section{Links Between Psychophysiological Evolution at Week 4 and Clinical Scores at Week 8}

A multiple regression with the mean differences between baseline and week 4 and group allocation (venlafaxine ER vs. applied relaxation) as independent variables, and with HAM-A scores at week 8 as outcome, shows that a reduction in frontal EMG values (neutral words condition) at week 4 is significantly associated with a decrease in HAM-A scores at week $8\left(P<0.0005\right.$, adjusted $\left.\mathrm{R}^{2}=25.2 \%\right)$. It was not observed as a group effect. Similar multiple regressions with other psychophysiological measures did not show any significant association with the evolution of HAM-A scores. A multiple regression with mean differences of psychophysiological measures between baseline and week 4 and group allocation (venlafaxine vs. applied relaxation) as independent variables, and with PSWQ score at week 8 as outcome, did not show any statistically significant effect. Furthermore, no group effect was observed.

\section{Links Between Psychophysiological Evolution at Week 8 and Clinical Outcome at Week 16}

For people who were switched to the combined treatment option, all conditions were analyzed by ANOVA for repeated measures with two factors: extension group (venlafaxine first and relaxation next; relaxation first and venlafaxine next) and remission group $(\mathrm{HAM}<8)$.

The results showed that people who achieved remission had a significantly higher mean score at week 12, higher than those who did not achieve remission. Time $\times$ HAM-A effects were observed on the frontal EMG in the following conditions: relaxation $(F=29.9, P<0.0005)$, anxiety-related words $(F=23.6, P<0.001)$, and calculation $(F=5.8, P<0.04)$. Patients who achieved remission and had relaxation treatment first and venlafaxine next had a significantly higher mean score at week 12 , higher than those who received the reverse. Time $\times$ HAM-A $\times$ extension group effects were observed for frontal EMG in the conditions relaxation $(F=16.7, P=0.003)$ and anxiety-related words $(F=9.4, P=0.01)$.

\section{Discussion}

The objective of the present study was to evaluate and compare the effects of venlafaxine and relaxation therapy on psychophysiological activity and reactivity and to assess the possible relationship of different psychophysiological variables with therapeutic efficacy. Furthermore, the study aimed to assess the impact of combination treatment in the case of non-remission after 8 weeks of treatment. 
At baseline, the clinical and electrophysiological measures were not associated. Furthermore, clinical outcomes at week 8 were not linked to initial psychophysiological measures.

Independent of a treatment-allocation effect, a reduction of frontal EMG values at week 4 is significantly associated with a decrease of HAM-A scores at week 8 . The frontal EMG response at week 4 seems to be a predictor of treatment response. This is in accordance with the consideration that the frontalis primarily reflects affective states [9], as well as with previous studies showing that changes in psychophysiological measurements may predict clinical change upon pharmacological or cognitive behavioral treatment of panic disorder [39] and post-traumatic stress disorder [40].

Whereas treatment groups did not differ in clinical outcomes, electrophysiological processes seemed to differ. At week 4, the applied relaxation group had lower electrophysiological activity than the venlafaxine group. Furthermore, consideration of the relation between the change in electrophysiological measures between baseline and week 4 , and of treatment group and remission at week 8, showed that the applied relaxation group appeared to have lower mean scores in comparison with the venlafaxine ER group. A similar phenomenon was found at week 12 for remitted people and at week 16 for those who had relaxation treatment first (introduction of venlafaxine ER at week 8). These observations are possibly related to the noradrenergic activity of venlafaxine, which led at the beginning of treatment to an increased catecholaminergic tone.

In the present study, no group differences were found in treatment responses. The addition of venlafaxine ER to those who do not respond to applied relaxation therapy and vice versa increased the number of responses. These results led to the consideration of this strategy in the case of initial treatment resistance. These results suggest that a combination of venlafaxine and applied relaxation enhances treatment response in the case of initial failure.

The limitations of the study include a relatively small sample size and the lack of longterm follow-up. Furthermore, the study cannot provide definitive conclusions on the combination treatment because of the lack of a control group (i.e. non-responding people in treatment continuation or a placebo group). The study does, however, highlight some of the electrophysiological processes occurring during venlafaxine and relaxation treatment and contributes preliminary results on the utility of the combination of both treatments in the case of initial failure.

Acknowledgments The study was supported by an unrestricted Grant from Wyeth Pharmaceuticals, Switzerland. The authors reported no other conflicts of interest in relation with the present work.

\section{References}

1. Wittchen HU, Kessler RC, Beesdo K, Krause P, Hofler M, Hoyer J.: Generalized anxiety and depression in primary care: prevalence, recognition, and management. The Journal of Clinical Psychiatry 63 Suppl 8:24-34, 2002.

2. Zou C, Ding X, Flaherty JH, Dong B.: Clinical efficacy and safety of fluoxetine in generalized anxiety disorder in Chinese patients. Neuropsychiatric Disease and Treatment 9:1661-70, 2013. doi:10.2147/ NDT.S38899.

3. Gerard A, Liard F, Crochard A, Goni S, Millet B.: Disability in patients consulting for anxiety or mood disorders in primary care: response to antidepressant treatment. Neuropsychiatric Disease and Treatment 8:605-14, 2012. doi:10.2147/NDT.S34132. 
4. Kittirattanapaiboon P, Suttajit S, Junsirimongkol B, Likhitsathian S, Srisurapanont M.: Suicide risk among Thai illicit drug users with and without mental/alcohol use disorders. Neuropsychiatric Disease and Treatment 10:453-8, 2014. doi:10.2147/NDT.S56441.

5. Yuce M, Zoroglu SS, Ceylan MF, Kandemir H, Karabekiroglu K.: Psychiatric comorbidity distribution and diversities in children and adolescents with attention deficit/hyperactivity disorder: A study from Turkey. Neuropsychiatric Disease and Treatment 9:1791-9, 2013. doi:10.2147/NDT.S54283.

6. Becker ES, Rinck M, Roth WT, Margraf J.: Don't worry and beware of white bears: Thought suppression in anxiety patients. Journal of Anxiety Disorders 12(1):39-55, 1998.

7. Chen J, Wang Z, Wu Y, Cai Y, Shen Y, Wang L, et al.: Differential attentional bias in generalized anxiety disorder and panic disorder. Neuropsychiatric Disease and Treatment 9:73-80, 2013. doi:10. 2147/NDT.S36822.

8. Tanaka M, Yoshida M, Emoto H, Ishii H.: Noradrenaline systems in the hypothalamus, amygdala and locus coeruleus are involved in the provocation of anxiety: Basic studies. European Journal of Pharmacology 405(1-3):397-406, 2000.

9. McLeod DR, Hoehn-Saric R, Labib AS, Greenblatt DJ.: Six weeks of diazepam treatment in normal women: Effects on psychomotor performance and psychophysiology. Journal of Clinical Psychopharmacology 8(2):83-99, 1988.

10. Naveteur J, Baque EF.: Electrodermal asymmetry and vigilance in negative emotion, anxiety and stress. International Journal of Psychophysiology 6(4):339-42, 1988.

11. Quermonne MA, Nammathao B, Louchahi-Raoul J, Marcy R.: Skin conductance reaction (SCR)habituation test, an elementary model of anxiety as a tool to assess anxiogenic activities of some drugs. Progress in Neuro-Psychopharmacology \& Biological Psychiatry 17(2):311-8, 1993.

12. Hazlett RL, McLeod DR, Hoehn-Saric R.: Muscle tension in generalized anxiety disorder: Elevated muscle tonus or agitated movement?. Psychophysiology 31(2):189-95, 1994.

13. Hoehn-Saric R, McLeod DR, Zimmerli WD.: Somatic manifestations in women with generalized anxiety disorder. Psychophysiological responses to psychological stress. Archives of General Psychiatry 46(12):1113-9, 1989.

14. Davidson JR, DuPont RL, Hedges D, Haskins JT.: Efficacy, safety, and tolerability of venlafaxine extended release and buspirone in outpatients with generalized anxiety disorder. The Journal of Clinical Psychiatry. 60(8):528-35, 1999.

15. Hoehn-Saric R, McLeod DR.: Anxiety and arousal: Physiological changes and their perception. Journal of Affective Disorders. 61(3):217-24, 2000.

16. Stein MB, Pollack MH, Bystritsky A, Kelsey JE, Mangano RM.: Efficacy of low and higher dose extended-release venlafaxine in generalized social anxiety disorder: A 6-month randomized controlled trial. Psychopharmacology (Berl) 177(3):280-8, 2005. doi:10.1007/s00213-004-1957-9.

17. Baldwin DS, Allgulander C, Bandelow B, Ferre F, Pallanti S.: An international survey of reported prescribing practice in the treatment of patients with generalised anxiety disorder. The World Journal of Biological Psychiatry 13(7):510-6, 2012. doi:10.3109/15622975.2011.624548.

18. Ereshefsky L, Dugan D.: Review of the pharmacokinetics, pharmacogenetics, and drug interaction potential of antidepressants: Focus on venlafaxine. Depression and Anxiety 12 Suppl 1:30-44, 2000. doi:10.1002/1520-6394(2000)12.

19. Rickels K, Pollack MH, Sheehan DV, Haskins JT.: Efficacy of extended-release venlafaxine in nondepressed outpatients with generalized anxiety disorder. The American Journal of Psychiatry 157(6):968-74, 2000.

20. Gelenberg AJ, Lydiard RB, Rudolph RL, Aguiar L, Haskins JT, Salinas E.: Efficacy of venlafaxine extended-release capsules in nondepressed outpatients with generalized anxiety disorder: A 6-month randomized controlled trial. JAMA 283(23):3082-8, 2000.

21. Olatunji BO, Cisler JM, Deacon BJ.: Efficacy of cognitive behavioral therapy for anxiety disorders: A review of meta-analytic findings. The Psychiatric Clinics of North America 33(3):557-77, 2010. doi:10. 1016/j.psc.2010.04.002.

22. Kawaguchi A, Watanabe N, Nakano Y, Ogawa S, Suzuki M, Kondo M, et al.: Group cognitive behavioral therapy for patients with generalized social anxiety disorder in Japan: Outcomes at 1-year follow up and outcome predictors. Neuropsychiatric Disease and Treatment 9:267-75, 2013. doi:10. 2147/NDT.S41365

23. Borgeat F, Stankovic M, Khazaal Y, Rouget BW, Baumann MC, Riquier F, et al.: Does the form or the amount of exposure make a difference in the cognitive-behavioral therapy treatment of social phobia? The Journal of Nervous and Mental Disease 197(7):507-13, 2009. doi:10.1097/NMD.0b013e3181aacc08

24. Lang AJ.: Treating generalized anxiety disorder with cognitive-behavioral therapy. The Journal of Clinical Psychiatry 65 Suppl 13:14-9, 2004. 
25. Barlow DH, Rapee RM, Brown TA.: Behavioral treatment of generalized anxiety disorder. Behavior Therapy 23:551-6, 2003.

26. Fisher PL, Durham RC.: Recovery rates in generalized anxiety disorder following psychological therapy: An analysis of clinically significant change in the STAI-T across outcome studies since 1990. Psychological Medicine 29(6):1425-34, 1999.

27. Malyszczak K, Kiejna A, Grzesiak M.: Factorial structure of hamilton anxiety rating scale. Psychiatria Polska 32(6):771-9, 1998.

28. Maier W, Buller R, Philipp M, Heuser I.: The hamilton anxiety scale: Reliability, validity and sensitivity to change in anxiety and depressive disorders. Journal of Affective Disorders 14(1):61-8, 1988.

29. Beck AT, Guth D, Steer RA, Ball R.: Screening for major depression disorders in medical inpatients with the beck depression inventory for primary care. Behaviour Research and Therapy 35(8):785-91, 1997.

30. Meyer TJ, Miller ML, Metzger RL, Borkovec TD.: Development and validation of the penn state worry questionnaire. Behaviour Research and Therapy 28(6):487-95, 1990.

31. Gosselin P, Dugas MJ, Ladouceur R, Freeston MH. Evaluation of worry: Validation of a French translation of the penn state worry questionnaire. L'Encephale 27(5):475-84, 2001.

32. Silva FT, Leite JR.: Physiological modifications and increase in state anxiety in volunteers submitted to the Stroop Color-Word interference test: A preliminary study. Physiology and Behavior 70(1-2):113-8, 2000.

33. Tulen JH, Moleman P, van Steenis HG, Boomsma F.: Characterization of stress reactions to the Stroop Color Word Test. Pharmacology, Biochemistry, and Behavior 32(1):9-15, 1989.

34. Renaud P, Blondin JP.: The stress of Stroop performance: Physiological and emotional responses to color-word interference, task pacing, and pacing speed. International Journal of Psychophysiology 27(2):87-97, 1997.

35. McLeod DR, Hoehn-Saric R, Stefan RL.: Somatic symptoms of anxiety: Comparison of self-report and physiological measures. Biological Psychiatry 21(3):301-10, 1986.

36. Becker ES, Rinck M, Margraf J, Roth WT.: The emotional Stroop effect in anxiety disorders: General emotional or disorder specificity?. Journal of Anxiety Disorders 15(3):147-59, 2001.

37. Becker ES, Roth WT, Andrich M, Margraf J.: Explicit memory in anxiety disorders. Journal of Abnormal Psychology 108(1):153-63, 1999.

38. Becker AE, Burwell RA, Gilman SE, Herzog DB, Hamburg P.: Eating behaviours and attitudes following prolonged exposure to television among ethnic Fijian adolescent girls. The British Journal of Psychiatry 180:509-14, 2002.

39. Slaap BR, Boshuisen ML, van Roon AM, den Boer JA.: Heart rate variability as predictor of nonresponse to mirtazapine in panic disorder: A preliminary study. International Clinical Psychopharmacology 17(2):69-74, 2002.

40. Pitman RK, Orr SP, Altman B, Longpre RE, Poire RE, Macklin ML, et al.: Emotional processing and outcome of imaginal flooding therapy in Vietnam veterans with chronic posttraumatic stress disorder. Comprehensive Psychiatry 37(6):409-18, 1996.

Daniele Zullino MD is a specialist in psychiatry and psychotherapy. He is the head of the Division of Addictology at the University Hospitals of Geneva, Switzerland and professor at the Geneva University. He has more than 200 scientific publications.

Anne Chatton MA is statistician. She has a number of publications in the field of mental health.

Emmanuelle Fresard MA was psychologists and Cognitive Behavioral Therapists.

Miroslava Stankovic MA was psychologists and Cognitive Behavioral Therapists.

Guido Bondolfi MD is a specialist in psychiatry and psychotherapy. He is the head of the Anxiety Disorders Unit at the University Hospitals of Geneva, Switzerland and professor at the Geneva University. He is a Cognitive Behavioral Therapists involved in teaching and research in this field.

François Borgeat MD is a specialist in psychiatry and psychotherapy. He was involved in numerous research on cognitive and behavior therapy and in psychophysiology. He is Professor at the Lausanne University and at the Montreal University. He was the head of the University Department of psychiatry at Lausanne in Switzerland. 
Yasser Khazaal MD is a specialist in psychiatry and psychotherapy in the Department of mental health and psychiatry at the University Hospitals of Geneva, Switzerland. He has more than 150 scientific publications, mainly on cognitive behavior therapy and pharmacotherapy as well as internet-related behaviors. He is a Cognitive Behavioral Therapists involved in teaching and research in this field. 